\title{
Management of Klinefelter syndrome during transition
}

\author{
Inge Gies ${ }^{1,3,+}$, David Unuane ${ }^{2,3}$, Brigitte Velkeniers ${ }^{2,3}$ and Jean De Schepper ${ }^{1,2,3}$ \\ ${ }^{1}$ Division of Pediatric Endocrinology, ${ }^{2}$ Department of Endocrinology and ${ }^{3}$ Klinefelter Clinic, UZ Brussel, \\ Vrije Universiteit Brussel, Brussels, Belgium \\ ${ }^{\dagger}$ (I Gies is now at Department of Pediatrics, UZ Brussel, Laarbeeklaan 101, 1090 Brussels, Belgium)
}

Correspondence should be addressed to I Gies

Email

Inge.Gies@uzbrussel.be

\begin{abstract}
Klinefelter syndrome (KS) is the most common sex chromosomal disorder in males. Key findings in older adolescents and young men are small testes with variable hypo-androgenism, but almost universal azoospermia, most frequently in combination with a history of learning difficulties and behavior problems. Males with KS may come to medical attention through different medical presentations, given its association with several congenital malformations, and psychiatric, endocrine, and metabolic disorders. Preventive care is to be provided from diagnosis, preferentially through a multidisciplinary approach, including that from an endocrinologist, clinical psychologist or psychiatrist, neurologist, urologist, geneticist, sexologist, and a fertility team. Accurate information about the condition and assessment of associated medical conditions should be offered at diagnosis and should be followed by psychological counseling. Medical treatment during transition into adulthood is focused on fertility preservation and testosterone replacement therapy in the case of hypo-androgenism, and alleviation of current or future consequences of testicular fibrosis. However, more research is needed to determine the need for pro-active testosterone treatment in adolescence, as well as the conditions for an optimal testosterone replacement and sperm retrieval in adolescents and young men with KS. Furthermore, screening for associated diseases such as metabolic syndrome, autoimmune diseases, thyroid dysfunction, and malignancies is warranted during this period of life. The practical medical management during transition and, more specifically, the role of the endocrinologist are discussed in this article.
\end{abstract}

\section{Introduction}

\section{Incidence}

Klinefelter syndrome (KS) or 47,XXY syndrome occurs in about $152-223$ cases per 100000 males and is therefore the most frequent (numerical) chromosomal disorder in males $(1,2,3)$. Besides the classical 47,XXY karyotype (present in $80-85 \%$ of subjects with KS), other chromosomal

\section{Invited Author's profile}

Jean De Schepper is associate Professor of Pediatrics and Head of the Unit of Pediatric Endocrinology at the University Hospital, Free University of Brussels (VrijeUniversiteitBrussel), Belgium. He heads the Pediatric and Adolescent Endocrinology and Diabetology Clinic, University Hospital Ghent, where he also holds a Consultant appointment for adolescent endocrinology at the Endocrinology Department. He has more than one hundred publications on several topics in pediatric endocrinology (bone mineralization, GH therapy, outcome of fertility treatments). He recently joined the research group 'Biology of the testes (BITE)' at the Faculty of Medicine, Free University of Brussels. He is a founding member of the Belgian Study Group for Pediatric Endocrinology and the Klinefelter Clinic at the University Hospital, Free University of Brussels.

(C) 2014 European Society of Endocrinology Printed in Great Britain
Published by Bioscientifica Ltd. 
abnormalities, such as the presence of more than two supra-numerous $\mathrm{X}$ chromosomes, a $48, \mathrm{XXYY}$ or $46, \mathrm{XY} /$ $47, \mathrm{XXY}$ karyotype, and other types of mosaicisms, can be present $(4,5)$. In general, Klinefelter mosaics $(47, \mathrm{XXY} /$ $46, \mathrm{XY})$ are less severely affected, whereas higher aneuploidy is associated with a more severe phenotype (6). This variability in karyotype explains to some extent the wide clinical spectrum of the syndrome. In this article, we will focus on the classical 47,XXY KS.

\section{Genotype-phenotype correlation}

The phenotype is presumed to be the consequence of the presence of non-inactivated extra genes from the supranumerous $\mathrm{X}$ chromosome, although other genetic mechanisms are possible. The supernumerary X chromosome is of maternal origin in only $50 \%$, and a maternal or paternal age effect in the occurrence of KS is not clearly established. The CAG repeat number in the androgen receptor seems to be related to some of the physical signs (e.g. micropenis, tall stature, and gynecomastia) $(7,8,9)$. Prenatal diagnosis of KS is mainly a chance finding. Increased paternal meiotic alterations and an increase in routinely performed prenatal investigations might be responsible for an increased prevalence of KS in recent decades $(10,11,12)$.

\section{Comorbidities}

Patients with KS have an increased (by 70\% overall) rate of hospitalization, mainly due to congenital malformations, and psychiatric, endocrine, and metabolic disorders (13). The expected life span of patients with KS was found to be reduced by 1.5-2 years, with increased mortality from a range of different disorders, including diabetes, lung disease, epilepsy, cerebrovascular disease, and vascular insufficiency of the intestine (14). The recently observed reduced arterial diameters in patients with KS, which lead to a reduced organ perfusion, might be an important risk factor for increased mortality (15). On the other hand, confounding factors, including a lower socioeconomic status of many patients with KS, might explain some, but not all, of the excess mortality in patients with KS (16).

\section{Multidisciplinary approach}

Given the increased risk for several serious diseases and higher risk for hospitalization, a regular (at least annually) medical follow-up, preferentially by a multidisciplinary team, is needed $(17,18)$. Endocrinologists should be involved, especially during transition, when the consequences of hypo-androgenism might start to develop. However, during this particular period, when parental input in medical care stops or diminishes greatly, patients with KS may be easily lost from medical care, as these young men do not always assume the requested responsibility for self-care (19). A multidisciplinary joined workout with members of both the pediatric and the adult team at the moment of transition is recommended to establish a good relation between the patient with KS and his new medical team and secure a proper management.

\section{Diagnosis of KS during transition}

\section{Clinical symptoms}

Insufficient awareness of the presenting symptoms of KS, as well as the wide spectrum of symptoms, disables an early diagnosis: only a minority (about 10\%) of patients with KS are currently diagnosed before puberty $(3,20)$. Cryptorchidism, behavioral problems, and learning disabilities as well as tall stature may suggest the diagnosis before puberty. Gynecomastia and micro-orchidism (mostly from the age of 14 years), as well as a poor muscular bulk with excessive long legs, small shoulders and broad hips, and a non-familial obesity, are all clinical clues of KS in late adolescence (21). KS is, however, most often diagnosed in adulthood, when men are evaluated for symptomatic hypogonadism, infertility, and/or sexual dysfunction.

Cardinal stigmata of KS include the small testes together with elevated serum FSH concentrations in virtually all young adult patients with KS. While hypoandrogenism occurs in most of the affected patients, its physical and biochemical abnormalities may be absent at first presentation $(21,22)$.

\section{Genetic testing}

Routine karyotyping is therefore advocated in all adolescents and young men with small testes, hypergonadotropic hypogonadism, and eventually diagnosed non-obstructive azoospermia (20).

Standard lymphocytic karyotyping is advocated to confirm the diagnosis of KS cytogenetically, but in case of a negative result associated with a suggestive clinical presentation, a complementary FISH study with specific $\mathrm{X}$ and $\mathrm{Y}$ markers in at least 100 interphase spreads is required to detect mosaicism, especially if $<20$ peripheral lymphocytes were examined by standard chromosome 
staining techniques (23). Karyotyping from skin fibroblasts or testicular biopsy samples can be requested, in case of normal FISH findings in lymphocytes, as karyotype analysis may overlook tissue-specific mosaic KS patterns (4).

\section{Providing psychological support and referral for psychiatric treatment}

\section{Psychological support}

The diagnosis of $\mathrm{KS}$ is difficult to accept for many adolescents and young men. The connation of a 'female' $\mathrm{X}$ chromosome as well as the presence of a poor muscular build with small shoulders, limited beard growth, and gynecomastia with feminine fat distribution can affect a young man's view of his masculinity, sexuality, and selfimage. These issues can be addressed by early psychological counseling. Therefore, psychological support should be considered a standard practice in the care of adolescents and men with KS.

Compared with their peers, many adolescents with KS consider themselves more sensitive, introspective, and insecure and have less interest in girls $(24,25)$. Furthermore, an increased incidence of anxiety, depression, and substance abuse has been reported in adolescents with KS (26). Attention deficit/hyperactivity disorders and autism spectrum disease are in particular more frequently diagnosed in patients with KS.

For most, but not all, adolescents and young men with $\mathrm{KS}$, infertility is the most difficult problem to deal with psychologically. Many patients with KS do not want to discuss their fertility problem with their family members and/or friends and need psychological support to overcome their suffering. A fertility counselor should therefore be involved to discuss the implications of testicular sperm extraction (TESE), artificial insemination with donor sperm, and/or adoption.

\section{Psychiatric conditions}

In $20-25 \%$ of adolescents with KS, a delay in scholastic and vocational achievement is noted. If learning problems, such as dyslexia, impairment of verbal and non-verbal memory, or planning problems, are not recognized and addressed, additional behavioral problems may emerge as a consequence of unmet needs and increased frustration. On the other hand, social incompetence and problems with control of aggressive behavior might increase the risk for scholastic failure (25).
Patients with KS are especially at risk for several psychiatric disorders, such as schizophrenia and psychotic disorders, which need an intense psychiatric treatment (27). In addition, men with KS have an increased risk of being convicted for criminality, although this might be explained by their lower socioeconomic status (28).

\section{Instauration of testosterone replacement treatment}

\section{Occurrence of hypo-androgenism}

While a normal testicular growth and testosterone increase occurs in boys with KS at the onset of puberty, an arrest or even an involution of the testes from mid-puberty is observed in most, but not all, adolescents $(29,30,31)$. However, most adolescents with KS pass through puberty normally, without any symptoms of hypogonadism, achieving a normal adult penis size and pubic hair development. During the transition period, the hypo-androgenism is rather relative than absolute with serum levels of testosterone in the low normal range $(30,32)$. In up to two-thirds of adult (20-40 years old) men with $\mathrm{KS}$, normal testosterone concentrations can be measured (33), even if their testes are in general very small (below $6 \mathrm{ml}$ at ultrasound) $(34,35)$.

\section{Preventive testosterone supplementation}

To secure a proper masculine sexual development (muscle strength, beard growth, and voice deepening) and to prevent long-term deleterious consequences of hypogonadism on bone development and lipid and glucose metabolism abnormalities (insulin resistance, and abdominal obesity), early 'preventive' testosterone supplementation in adolescents with KS has been advocated in the literature $(18,36,37)$. This attitude is not underpinned by evidence-based data, as no controlled trials have been performed.

Testosterone supplementation in adolescence Increased energy and endurance as well as improved mood and scholastic performance have been observed during testosterone treatment of adolescents with KS $(38,39)$. In a small retrospective study of ten young men with KS, preservation of verbal fluency was observed in five testosterone-treated patients since adolescence (40). However, all available studies on testosterone in adolescents with KS used a cross-sectional design and in none of them a standardized testosterone treatment was given. 
Furthermore, a biased impact of a regular medical attention on well-being (gain in self-confidence, and increased attention to scholastic progress) of the testosterone-treated boys cannot be excluded. In none of the studies performed till now, a difference on cognitive performance between testosterone-treated and untreated adolescents with KS could be observed $(38,40,41)$. Furthermore, Aksglaede et al. (42) and Bojesen et al. (43) described that testosterone treatment could only partially correct the unfavorable muscle:fat ratio in adolescents with KS. An unfavorable body composition, an increased leg length, and a poor muscle development as well as signs of the metabolic syndrome have been observed before puberty and might thus be inherent to the KS genotype and, therefore, not an indication for early 'preventive' testosterone therapy $(42,44)$.

As summarized in Table 1 , the additional value of testosterone therapy in asymptomatic young men with KS having normal testosterone levels and elevated gonadotropins remains unsettled, but yearly determination of serum testosterone is recommended from the age of 14 years on, given the wide variability in the onset of Leydig cell failure in patients with KS.

Testosterone supplementation in adulthood $\boldsymbol{\wedge}$ Not surprisingly, testosterone supplementation in young adult men with serum testosterone level in the lower half of the normal range did not result in significant changes in bone mineralization, body composition, or quality of life $(43,45,46)$. No increase in quality of life was observed in testosterone-treated men with KS having normal testosterone values (47). Furthermore, the effect of testosterone treatment on physical fatigue and muscular development at this particular stage of relative hypo-androgenism seems to be limited (48). No difference in exercise capacity and cardiopulmonary performance has been observed between newly diagnosed patients with KS and those treated with long-lasting intramuscular testosterone therapy (49). Till now, longitudinal changes in muscle force after testosterone treatment have not been studied in young or older men with KS. Wu et al. (50) could not observe an effect on self-reported mood, energy, or erectile responsiveness in men with KS having low normal testosterone levels and normal sexual activity. In addition, no improvement of gynecomastia should be expected from a systematic testosterone therapy in men with KS (51).

\section{Testosterone dosing}

When low or borderline low testosterone levels are documented in patients with KS, treatment is advocated if patients suffer from symptoms of hypo-androgenism (lack of energy, decreased libido, pubertal arrest, erectile dysfunction, abdominal fat accumulation, and anemia). Serum total testosterone levels below $12 \mathrm{nmol} / \mathrm{l}$ (between the ages of 20 and 30 years) are considered as cut-off values to initiate treatment in symptomatic patients (52). Testosterone monitoring is certainly needed after TESE, as restoration of testosterone level takes more than 12 months (53).

The optimal testosterone regimen for patients with KS during transition remains to be established. Among the wide variety of pharmaceutical forms available, the most commonly used are i.m. depot injections and transdermal gels. I.m. injection of testosterone esters, given monthly up to 3 months (for the undecanoate formulation), still remains the most popular way of testosterone administration in adolescence and young adulthood, given its ease

Table 1 Overview of studies on testosterone replacement therapy in KS during transition.

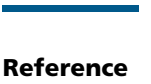

(59)

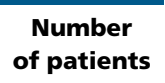

5

\begin{tabular}{c}
\hline $\begin{array}{c}\text { Age } \\
\text { (years) }\end{array}$ \\
\hline $9-24$
\end{tabular}

\begin{tabular}{l}
\hline Preparation \\
\hline Testosterone \\
enanthate \\
$200 \mathrm{mg} / 4$ \\
weeks i.m.
\end{tabular}

$14-20$

$12-17$
S.c. implantable $\mathrm{T}$ pellets

Testosterone gel $1 \%$ 0.5-5 g/day

Duration
(months)

7

(Te

Si

\begin{tabular}{l} 
Outcome \\
\hline Hyperpigmentation of \\
nipples \\
Temporary decrease \\
in gynecomastia \\
Significant change in \\
self-concept \\
Improvement of energy and \\
concentration; stability \\
of mood \\
No significant change \\
in gynecomastia
\end{tabular}

\section{Comments}

Non-standardized psychiatric interview

Non-standardized
questionnaires
Cough, acne, and headache
are the most frequent side
effects


of administration and low cost. Daily transdermal gel administration offers more stable testosterone levels and might be of help in patients with KS with discomfort from i.m. injections and/or presenting a more aggressive behavior, but carries a risk of inadvertent interpersonal transmission. Furthermore, dosing experience in adolescents with KS is still limited (54). Additionally, these preparations need daily application, which might favor a much lower compliance rate in adolescents. On the other hand, s.c. implantable testosterone pellets offer a viable option for non-compliant older adolescents or young men, but require surgical incision (55).

No specific dosage guidelines for testosterone therapy have been developed for patients with KS, although some endocrinologists prescribe rather higher dose regimens, given presumed androgen insensitivity in KS. A preferential $\mathrm{X}$ inactivation of the $\mathrm{X}$ chromosome with the shortest CAG repeat number in the androgen receptor, a low expression of the androgen receptor, and an increased aromatization from upregulation of the aromatase CYP19 (CYP19A1) gene might play a role in the lower efficacy of the androgen replacement therapy $(56,57,58)$.

While some endocrinologists are aiming at lownormal nadir levels before each testosterone injection, others prefer to obtain testosterone in mid-normal levels with normalization of serum LH. For topical testosterone gels, serum testosterone measurements $2 \mathrm{~h}$ after administration have been recommended (58). While gonadotropins are generally (but not always) suppressed after i.m. depot testosterone administration, no clinically significant changes in serum LH and FSH were noted in adolescents with KS receiving testosterone gels, despite the fact that total testosterone levels increased by 1.8 -fold (54).

We believe that, instead of focusing on biochemical parameters, the subjective symptoms of the patients (libido, increased energy level, erections and/or nocturnal emissions, and acne) should be taken into account in adapting testosterone treatment. In adolescents, the testosterone dosing should be titrated to a normal genital progression and eventually guided by changes in bone density and body composition, but must be weighed against potential adverse effects, such as gynecomastia, acne, and hyperpigmentation of the nipples (59). Patients with KS should also be observed for anxiety and depression, which might sometimes occur during testosterone treatment, requiring discontinuation of the therapy (60). Monitoring of glucose, hematocrit, and liver function tests during testosterone treatment is warranted. An increased incidence of type 2 diabetes has been observed in men with KS treated with testosterone during a median follow-up of 4 years, although only low to subnormal testosterone levels were observed during treatment (61). Elevated hematocrit values should be avoided in patients with KS, given their higher risk for thrombosis and thromboembolism. The effect of testosterone on prostate growth and serum prostate-specific antigen in KS and the specific role of the CAG repeat length in the androgen receptor and insulin resistance in modulating the effects of testosterone on the prostate require further study $(62,63)$.

\section{Testosterone and fertility}

Postponement of testosterone therapy should be discussed if early sperm cryopreservation is warranted, as chronic depot testosterone administration will suppress any remaining spermatogenesis. There is, however, actually some debate on the topic of early testosterone treatment and sperm retrieval rate at TESE (6), as Mehta et al. (64) described retrieval of spermatozoa at TESE in seven out of ten adolescents and young adults with KS, who received a dermal testosterone supplementation in combination with an aromatase inhibitor therapy for several years (1-5 years). Further studies are warranted to give appropriate counseling about this type of adjuvant hormonal treatment in adolescents, as bone mineralization and epiphyseal growth plate closure might be impaired during the long-standing anti-aromatase therapy.

\section{Referral for fertility preservation}

\section{Spermaturia and spermogram analysis}

KS is one of the most frequent causes of infertility, affecting $10-15 \%$ of azoospermic infertile men (65). Boys with KS progressively lose their spermatogenic capacity. From early puberty to mid-puberty, there is a histological change starting with relatively normal seminiferous tubules, reduced germ cells, and normal Sertoli/Leydig cells to the adult condition showing extensive fibrosis and hyalinization of the seminiferous tubules (66). Spontaneous fatherhood is extremely rare, while in up to $8 \%$ of men with KS, spermatozoa, although mostly with an aberrant motility and morphology, can be found in the ejaculate of men with KS $(50,67)$. Azoospermia is a very constant and universal finding in adolescents and adult men with KS, but can only reliably be diagnosed after a second careful examination of the sediment of centrifuged semen. The attempts of finding spermatozoa in morning urine of young adolescents have been unsuccessful 
$(29,68)$. Nevertheless, semen cryopreservation can be offered to every adolescent with KS in case of presence of spermaturia and/or detection of oligospermia in semen obtained by masturbation. From the age of 14 years, adolescents with KS can be asked to consider having a spermogram, as from that age biochemical and clinical signs of testicular failure can be observed and the majority of adolescents with KS will have some experience with masturbation or nocturnal sperm emissions. Adolescents with KS were indeed found to have a similar onset of masturbation compared with subjects without KS, which occurs approximately at the age of 13 years (58). It is, however, of importance to know that adolescents with KS have some delayed ability for ejaculation ( $\sim 9$ months difference between the first masturbation and the first ejaculation) and that their ejaculate volume is rather small $(58,69)$.

\section{TESE outcome}

TESE followed by ICSI, which was for the first time successfully described in men with KS in 1996, has dramatically changed the fertility outlook of men with KS (70). The follow-up of boys, born to KS fathers after this technique, did not show any higher incidence of phenotypic or chromosomal abnormalities (71). The few spermatogonia and spermatozoa locally produced in the hyalinized KS testes seem to have a $46, \mathrm{XY}$ constitution (72). The most recent TESE studies in KS demonstrate a sperm recovery rate of $66 \%$ and a live birth achievement of $45 \%$ (73). Pre-treatment with hCG and/or an aromatase blocker has been suggested to increase the sperm recovery at TESE in men with KS. These trials were, however, not controlled and in other types of male infertility no positive effect of its use has been reported (74).

Early referral of men with KS to a fertility clinic for TESE is proposed, as a younger age (below 32 years) is one of the few established prognostic parameters in predicting successful sperm retrieval $(74,75)$. The need to perform TESE already in adolescence can be questioned, as sperm was found in only one out of five adolescents with KS and in none of the seven adolescents with KS accepting TESE $(68,69)$. Cryopreservation of spermatogonial stem cells at testicular tissue sampling (by TESE or by micro-biopsy) is a more important experimental procedure, to be proposed to adolescents and young adults with KS in research settings until more data are available (76). As shown in Table 2, data on this new way of fertility preservation in adolescents with KS are still very limited. As unsuccessful sperm recovery might have an important emotional
Table 2 Overview of studies on testicular stem cell banking in KS during transition.

\begin{tabular}{|c|c|c|c|c|c|}
\hline \multirow[b]{2}{*}{ Reference } & \multirow{2}{*}{$\begin{array}{l}\text { Number } \\
\text { of patients }\end{array}$} & \multicolumn{2}{|c|}{ TESEI+ } & \multicolumn{2}{|c|}{ TESEI- } \\
\hline & & Number & Age (years) & Number & Age (years) \\
\hline (76) & 14 & 7 & $10.1-12.5$ & 7 & 11.7-14 \\
\hline (68) & 7 & 4 & $10.2-15.6$ & 3 & $13.6-15.6$ \\
\hline (64) & 10 & 7 & $14-22$ & 3 & $14-15$ \\
\hline
\end{tabular}

impact, psychological counseling before and after sperm collection and/or TESE is needed. The adolescent or young adult with KS should be involved in the fertility preservation process only if he is completely aware that a negative result is possible and if he has considered alternative options to father a child, and after obtaining consent from both the parents and the adolescent. The experimental nature of the whole procedure, combined with the need for surgical intervention on minors, strongly urges a cautious approach.

\section{Prevention and treatment of gynecomastia, abdominal obesity, metabolic syndrome, osteopenia, and thrombotic risk}

\section{Gynecomastia}

Gynecomastia and pseudogynecomastia are frequent findings in adolescents and men with KS, amounting up to $88 \%$ of patients $(77,78)$. In the absence of hypoandrogenism, no effect of testosterone treatment can be expected. Anti-estrogens (tamoxifen) can be used to treat gynecomastia, especially if the breast gland expansion is painful or occurred very rapidly, but results are variable as in patients without KS. Mastectomy can be performed in persistent gynecomastia and psychological discomfort. If associated with obesity, efforts to lose weight should precede surgical referral.

\section{Body composition and metabolic syndrome}

Many patients with KS present with altered body composition, even before puberty, showing an increase in total body and truncal fat and a decrease in lean body mass (42). In addition to a lower lean body mass, a lower physical fitness and lower muscle strength (both in biceps and quadriceps muscles) have been evidenced in males with KS $(9,79)$. Chronic fatigue and lower aptitude for sports are very frequent complaints of adolescents and young adults with KS and need further study. 
In comparison with a prevalence of $10 \%$ in the general population, almost half of men with KS were found to fulfill the criteria for the metabolic syndrome (49). The occurrence of metabolic syndrome in patients with KS has been associated with abdominal obesity, hypo-androgenism, and congenital or acquired insulin resistance. Patients with KS appear more at risk for primary insulin resistance: in males with KS (mean age of 22 years), who underwent an euglycemic hyperinsulinemic clamp study, a higher fasting insulinemia and a lower peripheral glucose uptake were documented in comparison with age- and BMI-matched subjects without KS (80). Furthermore, in a recent study on 89 pre-pubertal boys, $24 \%$ presented with insulin resistance and 37\% were found to have elevated LDL cholesterol (44). Surprisingly, arterial hypertension is not a frequent finding in patients with KS (49). The finding of dyslipidemia in adolescents with KS is a good opportunity to discuss lifestyle interventions, such as more regular weight-bearing exercise, limiting caffeine and alcohol intake, and smoking cessation, not only to prevent or reduce abdominal fat accumulation and its associated cardiovascular risk, but also to prevent insufficient bone accrual. Besides lifestyle changes, early instauration of metformin treatment might be beneficial in obese adolescents with KS gaining weight excessively and presenting elevated fasting insulin levels, but experience in adolescents with KS is lacking.

\section{Bone mass}

Decreased bone mass and osteoporosis are other frequent concerns in patients with KS. DXA scanning at diagnosis and by the end of puberty has been recommended for early detection of bone fragility (46). Indeed, men with KS have an increased risk of mortality related to an osteoporotic hip fracture, pointing to the need for preventive bone health measures in KS (5). Several associated conditions, such as hypo-androgenism, low muscle strength, and low physical activity, can be held responsible for a disturbed bone mass accrual during puberty and poor bone mass consolidation during young adulthood. Reduced bone mass in men with $\mathrm{KS}$ is not solely related to hypoandrogenemia, as it can also be found in patients with $\mathrm{KS}$ having normal testosterone concentrations. The low insulin-like factor 3 concentrations found in most adult men with KS have been related to a lower bone mass (81). Vitamin D deficiency is also very common in men with $\mathrm{KS}$, particularly in those with abdominal obesity and a sedentary lifestyle, and can contribute to a lower bone mass (46). Vitamin D and calcium supplements have been used in elderly men to reduce the risk of hip fracture, but there are no data of their efficacy in young men with KS. In north European countries, systematic vitamin D supplementation during winter months can be advised as a preventive and low-cost measure for optimizing bone health in adolescents and men with KS.

\section{Varicose veins and thromboembolism}

Specific attention should be given to the presence of varicose veins: venous stasis, eventually related to a basement membrane defect in venous valves, has been held responsible for the frequent occurrence of varicose veins and leg ulcers in patients with KS. Early surgery for varicose veins of the legs and early and aggressive treatment of leg ulcers are advised in men with KS, given their increased risk for deep venous thrombosis and pulmonary embolism (82). Concomitant obesity, an increased activity of plasminogen activator inhibitor, and abnormities in clotting have been advocated as major risk factors for thromboembolism in KS, but further studies are required to clarify these relationships $(83,84)$. Vascular morbidity in men with KS may also be increased, as an increased intima thickness of the carotids ( $+45 \%)$ in men with KS has been documented, and this finding was independent of testosterone treatment (49).

\section{Early detection of sexual dysfunction, malignancy, tooth decay, autoimmune diseases, and thyroid dysfunction}

\section{Sexual dysfunction}

Men with KS frequently seek medical aid because of sexual dysfunction (50). Discordant data on sexual desire, and lower coital and orgasm frequency have been published. Besides erectile dysfunction, hypoactive sexual desire was the most frequent complaint in men with KS attending an outpatient clinic for sexual problems (85). In this study, sexual problems were, however, not more frequent when compared with a testosterone-matched control group, confirming that the low sexual desire in $\mathrm{KS}$ is not only related to the testosterone deficiency.

\section{Malignancy}

Patients with KS have an increased risk of breast cancer (20-50 times more common) with an estimated frequency of $3.7-7.5 \%$ (5). An altered estradiol:testosterone ratio, long-standing gynecomastia, and obesity, as well as a 
genetic predisposition and possibly testosterone administration are among the proposed mechanisms for this particular finding. Clinical breast and axilla examination are recommended at each physical examination to detect in a timely fashion any suspicious sign of breast cancer (painless lump, nipple retraction, and bleeding from the nipple) or lymph node abnormality in men with KS. Extragonadal, mainly mediastinal, germ cell tumors are also more common (50 times higher than the general population) in men with KS, appearing mostly between the ages of 15 and 30 years, with an estimated prevalence of $1 \%$ (86). Precocious puberty in boys with KS and the presence of unexplained respiratory complaints in young adult men with KS should prompt additional investigations, including a chest X-ray. A recent large cohort study has also reported an increased mortality from lung cancer and non-Hodgkin lymphoma in KS, but no increased risk of testicular cancer or prostate cancer has been reported (5).

\section{Caries}

Caries is another frequent finding among patients with KS (87). Taurodontism, a dental condition caused by a greater pulp to enamel ratio, is present in $40-75 \%$ of patients with KS and holds a greater risk for tooth decay (88). Dental radiograph, rather than teeth inspection, usually establishes the diagnosis. Early referral to dental care and regular dental follow-up of patients with KS are required.

\section{Autoimmune diseases and thyroid dysfunction}

Autoimmune diseases, including systemic lupus erythematosus, Sjögren's syndrome, and rheumatoid arthritis, are frequently associated with KS. In particular, the risk for systemic lupus erythematosus, in comparison with the general male population, is 14-fold higher (86). Chronic estrogen stimulation and testosterone deficiency as well as a gene dosage effect of the $\mathrm{X}$ chromosome have been proposed as mechanisms underlying these observations $(89,90)$.

Data on the prevalence of thyroid disorders, especially autoimmune thyroiditis, in KS are limited. In a recent case-control study, a shift toward lower free thyroxin concentration without associated TSH elevation suggested a decrease in the set point of TSH control of thyroid function (91). As hypothyroidism is more frequently observed in adolescents and men with KS, annual thyroid function screening is recommended from early adolescence on wards $(13,92,93)$.

\section{Conclusion}

KS is a multiorgan and systemic disorder, reaching far beyond testicular failure. Patients with KS therefore need a regular medical follow-up with special attention for related comorbidities. Testosterone replacement therapy should not be considered as the Holy Grail for most of the complaints of patients with KS. Management of KS during transition should be organized by a multidisciplinary team to deal with all the aspects of the syndrome, in order to ultimately improve the quality of life and decrease the morbidity of the patients in the long term.

\section{Declaration of interest}

The authors declare that there is no conflict of interest that could be perceived as prejudicing the impartiality of the review.

\section{Funding}

This research did not receive any specific grant from any funding agency in the public, commercial, or not-for-profit sector.

\section{References}

1 Coffee B, Keith K, Albizua I, Malone T, Mowrey J, Sherman S \& Warren $\mathrm{S}$. Incidence of fragile $\mathrm{X}$ syndrome by newborn screening for methylated FMR1 DNA. American Journal of Human Genetics 200985 503-514. (doi:10.1016/j.ajhg.2009.09.007)

2 Herlihy A, Halliday J, Cock M \& McLachlan R. The prevalence and diagnosis rated of Klinefelter syndrome: an Australian comparison. Medical Journal of Australia 2011194 24-28.

3 Bojesen A, Juul S \& Gravholt C. Prenatal and postnatal prevalence of Klinefelter syndrome: a national registry study. Journal of Clinical Endocrinology and Metabolism 200388 622-626. (doi:10.1210/jc.2002021491)

4 Kamischke A, Baumgardt A, Horst J \& Nieschlag E. Clinical and diagnostic features of patients with suspected Klinefelter syndrome. Journal of Andrology 200324 41-48.

5 Swerdlow A, Higgins C, Schoemaker M, Wright A, Jacobs P \& United Kingdom Clinical Cytogenetics Group. Mortality in patients with Klinefelter syndrome in Britain: a cohort study. Journal of Clinical Endocrinology and Metabolism 200590 6516-6522. (doi:10.1210/jc. 2005-1077)

6 Paduch DA, Fine RG, Bolyakov A \& Kiper J. New concepts in Klinefelter syndrome. Current Opinion in Urology 200818 621-627. (doi:10.1097/ MOU.0b013e32831367c7)

7 Zinn AR, Ramos P, Elder FF, Kowal K, Samango-Sprouse C \& Ross JL. Androgen receptor CAG repeat length influences phenotype of 47,XXY (Klinefelter) syndrome. Journal of Clinical Endocrinology and Metabolism 200590 5041-5046. (doi:10.1210/jc.2005-0432)

8 Wikström AM, Painter JN, Raivio T, Aittomäki K \& Dunkel L. Genetic features of the $\mathrm{X}$ chromosome affect pubertal development and testicular degeneration in adolescent boys with Klinefelter syndrome. Clinical Endocrinology 200665 92-97. (doi:10.1111/j.1365-2265.2006. 02554.x)

9 Bojesen A, Hertz JM \& Gravholt CH. Genotype and phenotype in Klinefelter syndrome - impact of androgen receptor polymorphism 
and skewed X inactivation. International Journal of Andrology 201134 e642-e648. (doi:10.1111/j.1365-2605.2011.01223.x)

10 Morris J, Alberman E, Scott C \& Jacobs P. Is the prevalence of Klinefelter syndrome increasing? European Journal of Human Genetics $2008 \mathbf{1 6}$ 163-170. (doi:10.1038/sj.ejhg.5201956)

11 Lowe X, Eskenazi B, Nelson D, Kidd S, Alme A \& Wyrobek A. Frequency of XY sperm increases with age in fathers of boys with Klinefelter syndrome. American Journal of Human Genetics 200169 1046-1054. (doi:10.1086/323763)

12 Herlihy A \& Halliday J. Is paternal age playing a role in the changing prevalence of Klinefelter syndrome? European Journal of Human Genetics 200816 1173-1174. (doi:10.1038/ejhg.2008.96)

13 Bojesen A, Juul S, Birkebaek N \& Gravholt C. Morbidity in Klinefelter syndrome: a Danish register study based on hospital discharge diagnosis. Journal of Clinical Endocrinology and Metabolism 200691 1254-1260. (doi:10.1210/jc.2005-0697)

14 Bojesen A, Juul S, Birkebaek N \& Gravholt C. Increased mortality in Klinefelter syndrome. Journal of Clinical Endocrinology and Metabolism 200489 3830-3834. (doi:10.1210/jc.2004-0777)

15 Foresta C, Caretta N, Palego P, Ferlin A, Zuccarello D, Lenzi A \& Selice R. Reduced artery diameters in Klinefelter syndrome. International Journal of Andrology 201235 720-725. (doi:10.1111/j.1365-2605.2012. 01269.x)

16 Bojesen A, Stochholm K, Juul S \& Gravholt C. Socioeconomic trajectories affect mortality in Klinefelter syndrome. Journal of Clinical Endocrinology and Metabolism 201196 2098-2104. (doi:10.1210/jc. 2011-0367)

17 Tyler C \& Edman JC. Down syndrome, Turner syndrome, and Klinefelter syndrome: primary care throughout the life span. Primary Care 200431 627-648. (doi:10.1016/j.pop.2004.04.006)

18 Groth KA, Skakkebæk A, Høst C, Gravholt CH \& Bojesen A. Clinical review: Klinefelter syndrome - a clinical update. Journal of Clinical Endocrinology and Metabolism 201398 20-30. (doi:10.1210/jc. 2012-2382)

19 Ryan S. The adolescent and young adult with Klinefelter syndrome: ensuring successful transitions to adulthood. Pediatric Endocrinology Reviews 20108 (Suppl 1) 169-177.

20 Abdel-Razic MM, Abdel-Hamid IA, Elsobky E \& El-Dahtory F. Further evidence of the clinical, hormonal, and genetic heterogeneity of Klinefelter syndrome: a study of 216 infertile Egyptian patients. Journal of Andrology 201233 441-448. (doi:10.2164/jandrol.110. 011536)

21 Smyth CM \& Bremner WJ. Klinefelter syndrome. Archives of Internal Medicine 1998158 1309-1314. (doi:10.1001/archinte.158.12.1309)

22 Klinefelter HF, Reifenstein EC \& Albright F. Syndrome characterized by gynecomastia, aspermatogenesis without a-Leydigism, and increased excretion of follicle-stimulating hormone. Journal of Clinical Endocrinology and Metabolism 19422 615-627. (doi:10.1210/jcem-2-11-615)

23 Lenz P, Luetjens C, Kamischke A, Kühnert B, Kennerknecht I \& Nieschlag E. Mosaic status in lymphocytes of infertile men with or without Klinefelter syndrome. Human Reproduction 200520 1248-1255. (doi:10.1093/humrep/deh745)

24 Ratcliffe S, Bancroft J, Axworthy D \& McLaren W. Klinefelter's syndrome in adolescence. Archives of Disease in Childhood 198257 6-12.

25 Mandoki M, Sumner G, Hoffman R \& Riconda D. A review of Klinefelters's syndrome in children and adolescents. Journal of the American Academy of Child and Adolescent Psychiatry 199130 167-172. (doi:10.1097/00004583-199103000-00001)

26 Linden M, Bender B \& Robinson A. Sex chromosome tetrasomy and pentasomy. Pediatrics 199596 672-682.

27 DeLisi L, Friedrich U, Wahlstrom J, Boccio-Smith A, Forsman A, Eklund K \& Crow T. Schizophrenia and sex chromosome anomalies. Schizophrenia Bulletin 199420 495-505. (doi:10.1093/schbul/20.3.495)

28 Stochholm K, Bojesen A, Jensen AS, Juul S \& Gravholt CH. Criminality in men with Klinefelter's syndrome and XYY syndrome: a cohort study. BMJ Open 20122 e000650. (doi:10.1136/bmjopen-2011-000650)
29 Ratcliffe S. The sexual development of boys with the chromosome constitution 47,XXY (Klinefelter's syndrome). Clinics in Endocrinology and Metabolism 198211 703-716. (doi:10.1016/S0300-595X(82) 80008-X)

30 Bastida MG, Rey RA, Bergadá I, Bedecarrás P, Andreone L, del Rey G, Boywitt A, Ropelato MG, Cassinelli H, Arcari A et al. Establishment of testicular endocrine function impairment during childhood and puberty in boys with Klinefelter syndrome. Clinical Endocrinology 2007 67 863-870. (doi:10.1111/j.1365-2265.2007.02977.x)

31 Topper E, Dickerman Z, Prager-Lewin R, Kaufman H, Maimon Z \& Laron Z. Puberty in 24 patients with Klinefelter syndrome. European Journal of Pediatrics 1982139 8-12. (doi:10.1007/BF00442070)

32 Salbenblatt J, Bender B, Puck M, Robinson A, Faiman C \& Winter J. Pituitary-gonadal function in Klinefelter syndrome before and during puberty. Pediatric Research 198519 82-86. (doi:10.1203/00006450198501000-00022)

33 Aksglaede L, Andersson AM, Jørgensen N, Jensen TK, Carlsen E, McLachlan RI, Skakkebaek NE, Petersen JH \& Juul A. Primary testicular failure in Klinefelter's syndrome: the use of bivariate luteinizing hormone-testosterone reference charts. Clinical Endocrinology $2007 \mathbf{6 6}$ 276-281. (doi:10.1111/j.1365-2265.2006.02722.x)

34 Isidori A, Giannetta E \& Lenzi A. Male hypogonadism. Pituitary 200811 171-180. (doi:10.1007/s11102-008-0111-9)

35 Westlander G, Ekerhovd E, Granberg S, Hanson L, Hanson C \& Bergh C. Testicular ultrasonography and extende chromosome analysis in men with nonmosaic Klinefelter syndrome: a prospective study of possible predictive factors for successful sperm recovery. Fertility and Sterility 200175 1102-1105. (doi:10.1016/S0015-0282(01)01793-9)

36 Radicioni AF, Ferlin A, Balercia G, Pasquali D, Vignozzi L, Maggi M, Foresta C \& Lenzi A. Consensus statement on diagnosis and clinical management of Klinefelter syndrome. Journal of Endocrinological Investigation 201033 839-850. (doi:10.1007/BF03350351)

37 Mehta A \& Paduch DA. Klinefelter syndrome: an argument for early aggressive hormonal and fertility management. Fertility and Sterility 201298 274-283. (doi:10.1016/j.fertnstert.2012.06.001)

38 Nielsen J, Pelsen B \& Sorensen K. Follow-up of 30 Klinefelter males treated with testosterone. Clinical Genetics 198833 262-269. (doi:10.1111/j.1399-0004.1988.tb03447.x)

39 Caldwell PD \& Smith DW. The XXY (Klinefelter's) syndrome in childhood: detection and treatment. Journal of Pediatrics $1972 \mathbf{8 0}$ 250-258. (doi:10.1016/S0022-3476(72)80586-9)

40 Patwardhan AJ, Eliez S, Bender B, Linden MG \& Reiss AL. Brain morphology in Klinefelter syndrome: extra X chromosome and testosterone supplementation. Neurology $2000 \mathbf{5 4} 2218-2223$. (doi:10.1212/WNL.54.12.2218)

41 Ross J, Roeltgen D, Stefanatos G, Benecke R, Zeger M, Kushner H, Ramos P, Elder F \& Zinn A. Cognitive and motor development during childhood in boys with Klinefelter syndrome. American Journal of Medical Genetics. Part A 2008 146A 708-719. (doi:10.1002/ajmg.a. 32232)

42 Aksglaede L, Molgaard C, Skakkebaek NE \& Juul A. Normal bone mineral content but unfavourable muscle/fat ratio in Klinefelter syndrome. Archives of Disease in Childhood 200893 30-34. (doi:10.1136/ adc.2007.120675)

43 Bojesen A, Birkebæk N, Kristensen K, Heickendorff L, Mosekilde L, Christiansen JS \& Gravholt CH. Bone mineral density in Klinefelter syndrome is reduced and primarily determined by muscle strength and resorptive markers, but not directly by testosterone. Osteoporosis International 201122 1441-1450. (doi:10.1007/s00198-010-1354-7)

44 Bardsley MZ, Falkner B, Kowal K \& Ross JL. Insulin resistance and metabolic syndrome in prepubertal boys with Klinefelter syndrome. Acta Paediatrica 2011100 866-870. (doi:10.1111/j.1651-2227.2011. 02161.x)

45 Howell SJ, Radford JA, Adams JE, Smets EM, Warburton R \& Shalet SM. Randomized placebo-controlled trial of testosterone replacement in men with mild Leydig cell insufficiency following cytotoxic 
chemotherapy. Clinical Endocrinology 200155 315-324. (doi:10.1046/ j.1365-2265.2001.01297.x)

46 Ferlin A, Schipilliti M, Di Mambro A, Vinanzi C \& Foresta C. Osteoporosis in Klinefelter's syndrome. Molecular Human Reproduction 201016 402-410. (doi:10.1093/molehr/gaq026)

47 de Ronde W, de Haan A \& Drent ML. Quality of life is reduced in patients with Klinefelter syndrome on androgen replacement therapy. European Journal of Endocrinology 2009160 465-468. (doi:10.1530/ EJE-08-0689)

48 Manning MA \& Hoyme HE. Diagnosis and management of the adolescent boy with Klinefelter syndrome. Adolescent Medicine $2002 \mathbf{1 3}$ 367-374.

49 Pasquali D, Arcopinto M, Renzullo A, Rotondi M, Accardo G, Salzano A, Esposito D, Saldamarco L, Isidori AM, Marra AM et al. Cardiovascular abnormalities in Klinefelter syndrome. International Journal of Cardiology 2013168 754-759. (doi:10.1016/j.ijcard.2012.09.215)

$50 \mathrm{Wu}$ F, Bancroft J, Davidson D \& Nicol K. The behavioural effects of testosterone undecanoate in adult men with Klinefelter's syndrome: a controlled study. Clinical Endocrinology 198216 489-497. (doi:10.1111/j.1365-2265.1982.tb02763.x)

51 Lanfranco F, Kamischke A, Zitzmann M \& Nieschlag E. Klinefelter's syndrome. Lancet 2004364 273-283. (doi:10.1016/S0140-6736 (04)16678-6)

52 Nieschlag E. Klinefelter syndrome: the commonest form of hypogonadism, but often overlooked or untreated. Deutsches Ärzteblatt International 2013110 347-353.

53 Takada S, Tsujimura A, Ueda T, Matsuoka Y, Takao T, Miyagawa Y, Koga M, Takeyama M, Okamoto Y, Matsumiya K et al. Androgen decline in patients with nonobstructive azoospemia after microdissection testicular sperm extraction. Urology 200872 114-118. (doi:10.1016/ j.urology.2008.02.022)

54 Rogol AD, Swerdloff RS, Reiter EO, Ross JL, Zumbrunnen TL, Pratt GA, Brennan JJ, Benesh J, Kan-Dobrosky N \& Miller MG. A multicenter, open-label, observational study of testosterone gel (1\%) in the treatment of adolescent boys with Klinefelter syndrome or anorchia. Journal of Adolescent Health $2014 \mathbf{5 4} 20-25$. (doi:10.1016/j.jadohealth. 2013.07.021)

55 Moskovic DJ, Freundlich RE, Yazdani P, Lipshultz LI \& Khera M. Subcutaneous implantable testosterone pellets overcome noncompliance in adolescents with Klinefelter syndrome. Journal of Andrology 201233 570-573. (doi:10.2164/jandrol.111.013979)

56 Meurer M, Kuhnle U, Lindl U \& Keller U. Androgen receptors in Klinefelter's syndrome. Lancet 1993341 1351. (doi:10.1016/01406736(93)90865-E)

57 Zitzmann M, Depenbusch M, Gromoll J \& Nieschlag E. X-chromosome inactivation patterns and androgen receptor functionality influence phenotype and social characteristics as well as pharmacogenetics of testosterone therapy in Klinefelter patients. Journal of Clinical Endocrinology and Metabolism 200489 6208-6217. (doi:10.1210/jc. 2004-1424)

58 Wosnitzer MS \& Paduch DA. Endocrinological issues and hormonal manipulation in children and men with Klinefelter syndrome. American Journal of Medical Genetics. Part C, Seminars in Medical Genetics 2013 163C 16-26. (doi:10.1002/ajmg.c.31350)

59 Myhre SA, Ruvalcaba RH, Johnson HR, Thuline HC \& Kelley VC. The effects of testosterone treatment in Klinefelter's syndrome. Journal of Pediatrics 197076 267-276. (doi:10.1016/S0022-3476(70)80173-1)

60 Meikle AW, Dobs AS, Arver S, Caramelli KE, Sanders SW \& Mazer NA. Androgen replacement in the treatment of Klinefelter's syndrome: efficacy and safety of a nonscrotal permeation-enhanced testosterone transdermal system. Endocrine Practice 19984 17-22. (doi:10.4158/ EP.4.1.17)

61 Jiang-Feng M, Hong-Li X, Xue-Yan W, Min N, Shuang-Yu L, Hong-Ding X \& Liang-Ming L. Prevalence and risk factors of diabetes in patients with Klinefelter syndrome: a longitudinal observational study.
Fertility and Sterility 201298 1331-1335. (doi:10.1016/j.fertnstert.2012. 07.1122)

62 Shibasaki T, Sasagawa I, Suzuki Y, Yazawa H, Ichiyanagi O, Matsuki S, Miura M \& Nakada T. Effect of testosterone replacement therapy on serum PSA in patients with Klinefelter syndrome. Archives of Andrology 200147 173-176. (doi:10.1080/014850101753145861)

63 Selice R, Caretta N, Di Mambro A, Torino M, Palego P, Ferlin A \& Foresta C. Prostate volume and growth during testosterone replacement therapy is related to visceral obesity in Klinefelter syndrome. European Journal of Endocrinology 2013169 743-749. (doi:10.1530/ EJE-13-0488)

64 Mehta A, Bolyakov A, Roosma J, Schlegel P \& Paduch D. Successful testicular sperm retrieval in adolescents with Klinefelter syndrome with at least 1 year of topical testosterone and aromatase inhibitor. Fertility and Sterility 2013100 970-974. (doi:10.1016/j.fertnstert.2013.06.010)

65 Okada H, Fujioka H, Tatsumi N, Kanzaki M, Okuda Y, Fujisawa M, Hazama M, Matsumoto O, Gohji K, Arakawa S et al. Klinefelter's syndrome in the male infertility clinic. Human Reproduction $1999 \mathbf{1 4}$ 946-952. (doi:10.1093/humrep/14.4.946)

66 Gies I, De Schepper J, Goossens E, Van Saen D, Pennings G \& Tournaye H. Spermatogonial stem cell preservation in boys with Klinefelter syndrome: to bank or not to bank, that's the question. Fertility and Sterility 201298 284-289. (doi:10.1016/j.fertnstert.2012. 04.023)

67 Kitamura M, Matsumiya K, Koga M, Nishimura K, Miura H, Tsuji T, Matsumoto M, Okamoto Y \& Okuyama A. Ejaculated spermatozoa in patients with non-mosaic Klinefelter's syndrome. International Journal of Urology 20007 88-92.

68 Gies I, De Schepper J, Van Saen D, Anckaert E, Goossens E \& Tournaye H. Failure of a combined clinical- and hormonal-based strategy to detect early spermatogenesis and retrieve spermatogonial stem cells in $47, \mathrm{XXY}$ boys by single testicular biopsy. Human Reproduction 201227 998-1004. (doi:10.1093/humrep/des002)

69 Rives N, Milazzo JP, Perdrix A, Castanet M, Joly-Hélas G, Sibert L, Bironneau A, Way A \& Macé B. The feasibility of fertility preservation in adolescents with Klinefelter syndrome. Human Reproduction 201328 1468-1479. (doi:10.1093/humrep/det084)

70 Tournaye H, Staessen C, Liebaers I, Van Assche E, Devroey P, Bonduelle $\mathrm{M} \&$ Van Steirteghem A. Testicular sperm recovery in nine 47,XXY Klinefelter patients. Human Reproduction 199611 1644-1649. (doi:10.1093/oxfordjournals.humrep.a019462)

71 Schiff J, Palermo G, Veeck L, Goldstein M, Rosenwaks Z \& Schlegel P. Success of testicular sperm extraction and intracytoplasmic sperm injection in men with Klinefelter syndrome. Journal of Clinical Endocrinology and Metabolism 200590 6263-6267. (doi:10.1210/jc. 2004-2322)

72 Maiburg M, Repping S \& Giltay J. The genetic origin of Klinefelter syndrome and its effect on spermatogenesis. Fertility and Sterility 2012 98 253-260. (doi:10.1016/j.fertnstert.2012.06.019)

73 Fullerton G, Hamilton M \& Maheshwari A. Should non-mosaic Klinefelter syndrome men be labelled as infertile in 2009? Human Reproduction 201025 588-597. (doi:10.1093/humrep/dep431)

74 Ramasamy R, Ricci JA, Palermo GD, Gosden LV, Rosenwaks Z \& Schlegel PN. Successful fertility treatment for Klinefelter's syndrome. Journal of Urology 2009182 1108-1113. (doi:10.1016/j.juro.2009. 05.019)

75 Emre Bakircioglu M, Erden H, Faplancan T, Ciray N, Bener F \& Bahceci M. Aging may adversely affect testicular sperm recovery in patients with Klinefelter syndrome. Urology 200668 1082-1086. (doi:10.1016/j.urology.2006.05.028)

76 Wikstrom A, Raivio T, Hadziselimovic F, Wikstrom S, Tuuri T \& Dunkel L. Klinefelter syndrome in adolescence: onset of puberty is associated with accelerated germ cell depletion. Journal of Clinical Endocrinology and Metabolism 200489 2263-2270. (doi:10.1210/jc. 2003-031725) 
77 Visootsak J \& Graham JM Jr. Klinefelter syndrome and other sex chromosomal aneuploidies. Orphanet Journal of Rare Diseases 2006142. (doi:10.1186/1750-1172-1-42)

78 Yazici M, Sahin M, Bolu E, Gok DE, Taslipinar A, Tapan S, Torun D, Uckaya G \& Kutlu M. Evaluation of breast enlargement in young males and factors associated with gynecomastia and pseudogynecomastia. Irish Journal of Medical Science 2010179 575-583. (doi:10.1007/s11845009-0345-1)

79 East BW, Boddy K \& Price WH. Total body potassium content in males with X and Y chromosome abnormalities. Clinical Endocrinology 19765 43-51. (doi:10.1111/j.1365-2265.1976.tb03802.x)

80 Yesilova Z, Oktenli C, Sanisoglu S, Musabak U, Cakir E, Ozata M \& Dagalp K. Evaluation of insulin sensitivity in patients with Klinefelter's syndrome: a hyperinsulinemic euglycemic clamp study. Endocrine 2005 27 11-15. (doi:10.1385/ENDO:27:1:011)

81 Bay K, Hartung S, Ivell R, Schumacher M, Jürgensen D, Jorgensen N, Holm M, Skakkebaek $\mathrm{N} \&$ Andersson A. Insulin-like factor 3 serum levels in 135 normal men and 85 men with testicular disorders: relationship to the luteinizing hormone-testosterone axis. Journal of Clinical Endocrinology and Metabolism 200590 3410-3418. (doi:10.1210/ jc.2004-2257)

82 Campbell W \& Price W. Venous thromboembolic disease in Klinefelter's syndrome. Clinical Genetics 198119 275-280. (doi:10.1111/ j.1399-0004.1981.tb00709.x)

83 Zollner T, Veraart J, Wolter M, Hesse S, Villemur B, Wenke A, Werner R, Boehncke W, Jost S, Scharrer I et al. Leg ulcers in Klinefelter's syndrome - further evidence for an involvement of plasminogen activator inhibitor-1. British Journal of Dermatology 1997136 341-344. (doi:10.1111/j.1365-2133.1997.tb14940.x)

84 Gattringer C, Scheurecker C, Höpfl R \& Müller H. Association between venous leg ulcers and sex chromosome anomalies in men. Acta Dermato-Venereologica 201090 612-615. (doi:10.2340/00015555-0949)

85 Corona G, Petrone L, Paggi F, Lotti F, Boddi V, Fisher A, Vignozzi L, Balercia G, Sforza A, Forti G et al. Sexual dysfunction in subjects with
Klinefelter's syndrome. International Journal of Andrology 201033 574-580.

86 Hasle H, Mellembaard A, Nielsen J \& Hansen J. Cancer incidence in men with Klinefelter syndrome. British Journal of Cancer $1995 \mathbf{7 1}$ 416-420. (doi:10.1038/bjc.1995.85)

87 Palin-Palokas T, Alvesalo L, Takala I, Paunio K, Suoranta K \& Varrela J. Caries occurrence in Klinefelter syndrome men (47,XXY males). Proceedings of the Finnish Dental Society 199086 143-147.

88 Jorgenson R. The conditions manifesting taurodontism. American Journal of Medical Genetics 198211 435-442. (doi:10.1002/ajmg. 1320110408)

89 Sawalha AH, Harley JB \& Scofield RH. Autoimmunity and Klinefelter's syndrome: when men have two X chromosomes. Journal of Autoimmunity 200933 31-34. (doi:10.1016/j.jaut. 2009.03.006)

90 Koçar IH, Yesilova Z, Ozata M, Turan M, Sengül A \& Ozdemir I. The effect of testosterone replacement treatment on immunological features of patients with Klinefelter's syndrome. Clinical and Experimental Immunology 2000121 448-452. (doi:10.1046/j.1365-2249.2000. 01329.x)

91 Bjorn A, Bojesen A, Gravholt C \& Laurberg P. Hypothyroidism secondary to hypothalamic-pituitary dysfunction may be part of the phenotype in Klinefelter syndrome: a case-control study. Journal of Clinical Endocrinology and Metabolism 200994 2478-2481. (doi:10.1210/ jc.2009-0365)

92 Radicioni AF, De Marco E, Gianfrilli D, Granato S, Gandini L, Isidori AM \& Lenzi A. Strategies and advantages of early diagnosis in Klinefelter's syndrome. Molecular Human Reproduction 201016 434-440. (doi:10.1093/molehr/gaq027)

93 Aksglaede L, Link K, Giwercman A, Jørgensen N, Skakkebaek NE \& Juul A. 47,XXY Klinefelter syndrome: clinical characteristics and age-specific recommendations for medical management. American Journal of Medical Genetics. Part C, Seminars in Medical Genetics 2013 163C 55-63. (doi:10.1002/ajmg.c.31349)

Received 15 March 2014

Revised version received 24 April 2014

Accepted 30 April 2014 